ARTICLE

Received 29 Jul 2014 | Accepted 28 Aug 2014 | Published 30 Oct $2014 \quad$ DOI: 10.1038/ncomms6108

\title{
SHP-1-mediated inhibitory signals promote responsiveness and anti-tumour functions of natural killer cells
}

\author{
Charlotte Viant ${ }^{1,2,3}$, Aurore Fenis ${ }^{1,2,3}$, Gaëtan Chicanne ${ }^{4}$, Bernard Payrastre ${ }^{4}$, Sophie Ugolini $i^{1,2,3}$ \\ \& Eric Vivier ${ }^{1,2,3,5}$
}

Natural killer (NK) cells are cytotoxic innate lymphoid cells that are involved in immune defense. NK cell reactivity is controlled in part by MHC class I recognition by inhibitory receptors, but the underlying molecular mechanisms remain undefined. Using a mouse model of conditional deletion in NK cells, we show here that the protein tyrosine phosphatase SHP-1 is essential for the inhibitory function of NK cell MHC class I receptors. In the absence of SHP-1, NK cells are hyporesponsive to tumour cells in vitro and their early $\mathrm{Ca}^{2+}$ signals are compromised. Mice without SHP-1 in NK cells are unable to reject MHC class I-deficient transplants and to control tumours in vivo. Thus, the inhibitory activity of SHP-1 is needed for setting the threshold of NK cell reactivity.

\footnotetext{
${ }^{1}$ Centre d'Immunologie de Marseille-Luminy, Aix-Marseille University UM2, Parc Scientifique et Technologique de Luminy, Case 906, 13288 Marseille, France. ${ }^{2}$ Inserm U1104, 13288 Marseille, France. ${ }^{3}$ CNRS UMR7280, 13288 Marseille, France. ${ }^{4}$ INSERM, U1048 and Université Toulouse III, Institut de Maladies Métaboliques et Cardiovasculaires, CHU-Rangueil, F-31300 Toulouse, France. ${ }^{5}$ Service d'Immunologie, Assistance Publique-Hôpitaux de Marseille, Hôpital de la Conception, 13385 Marseille, France. Correspondence and requests for materials should be addressed to S.U.

(email: ugolini@ciml.univ-mrs.fr) or to E.V. (email: vivier@ciml.univ-mrs.fr).
} 
$\mathrm{N}$ atural killer (NK) cells are cytotoxic innate lymphoid cells (ILCs) that produce various chemokines and cytokines, including interferon- $\gamma(\text { IFN- } \gamma)^{1-3}$. NK cells are involved in the immune surveillance of tumours and microbes, such as viruses, fungi, intracytoplasmic bacteria and parasites ${ }^{4-6}$. Despite their classification as innate lymphocytes, it is becoming clear that NK cells also have adaptive features, including some memory properties in particular ${ }^{7,8}$.

NK cells identify their targets via a panel of cell surface receptors, including inhibitory receptors, adhesion molecules and activating receptors recognizing microbe-derived molecules and stress-induced self-derived molecules ${ }^{2}$. The inhibitory NK cell surface receptors interacting with major histocompatibility complex (MHC) class I molecules are the best characterized, and have been shown to contribute to host tolerance of NK cells ${ }^{9-11}$. When NK cells interact with cells expressing surface MHC class I, the engagement of their cognate inhibitory receptors induces inhibitory signals that limit NK cell activation. By contrast, when NK cells interact with cells with a low density of surface MHC class I, the lack of engagement of MHC class I-specific inhibitory receptors promotes NK cell activation. Consequently, NK cells can eliminate MHC class I-negative cells ${ }^{12,13}$.

However, no signs of NK cell-dependent autoimmunity have been detected in mice or humans with genetic defects, resulting in a lack of stable cell surface expression of MHC class I molecules ${ }^{14}$. In these MHC class I-deficient hosts, NK cells are present but hyporesponsive to various stimuli, providing a basis for selftolerance. This situation is not limited to MHC class I-deficient hosts, as subsets of $\mathrm{NK}$ cells lacking inhibitory cell surface receptors recognizing host $\mathrm{MHC}$ class I molecules are present in normal humans and mice ${ }^{14}$. Paradoxically, the sustained lack of engagement of inhibitory receptors is thus involved in establishing the hyporesponsiveness of NK cells observed in MHC class I-deficient hosts ${ }^{15-18}$. Nevertheless, the precise mechanisms by which the inhibitory receptors exert their effects on the acquisition or maintenance of NK cell functional competence, referred to as NK cell education or tuning, remain a matter of debate. It has been suggested that the recognition of MHC class I molecules by inhibitory receptors licences NK cells to acquire their effector functions, in a process referred to as arming ${ }^{19}$. Alternatively, it has been suggested that NK cells integrate activating signals that desensitize them, leading to their hyporesponsiveness, unless this effect is attenuated by the binding of inhibitory receptors to their MHC class I ligands, in a process referred to as disarming ${ }^{14}$. In both cases, the impact of MHC class I receptors on NK cell responsiveness does not follow an all-ornone law, instead following a rheostat model, in which NK cell reactivity increases quantitatively with each inhibitory receptor binding to self MHC class I molecules ${ }^{10,20}$.

NK cell inhibitory MHC class I receptors include killer cell Iglike receptors (KIR) in humans, inhibitory Ly49 receptors in the mouse and inhibitory CD94/NKG2A heterodimers in both species. All these inhibitory receptors harbour intracytoplasmic immunoreceptor tyrosine-based inhibition motifs (ITIMs), which are involved in their inhibitory function ${ }^{21,22}$. Following binding to MHC class I ligands, ITIMs undergo tyrosine phosphorylation, enabling them to recruit the protein tyrosine phosphatases SHP-1 and SHP-2 (refs 21,22). It has been suggested that inhibitory KIR function also involves phosphorylation of the Crk adaptor ${ }^{23,24}$. In mice, intact ITIMs are required for the function of MHC class I receptors in $\mathrm{NK}$ cell education ${ }^{15,25,26}$, but the reported role of SHP-1 remains controversial. Studies of SHP-1-deficient mice with chimeric bone marrow have shown SHP-1 to be dispensable for NK cell education ${ }^{15}$, whereas a transdominant negative form of SHP-1 was found to affect NK cell responsiveness ${ }^{27}$. However, SHP-1 is broadly expressed in haematopoietic cells, and the exploration of NK cell development and function in the absence of SHP-1 is hampered by the major inflammatory conditions prevailing in the two mouse models of SHP-1-deficiency: motheaten $\left(P t p n 6^{\mathrm{me} / \mathrm{me}}\right)$ and motheaten-viable (Ptpn $6^{\mathrm{me}-\mathrm{v} / \mathrm{me}-\mathrm{v}}$ ) mice. Both these models display a complex inflammatory phenotype, including sterile pneumonia, dermatitis and autoimmunity, leading to premature death ${ }^{28}$. It is thus difficult to discriminate between the direct and indirect defects of an absence of SHP-1 on NK cells. We addressed this question, by creating a model of conditional Ptpn6 deletion, to dissect the role of SHP-1 in NK cells and the mechanisms by which the inhibitory Ly49 and CD94/NKG2A receptors affect NK cells. We found that in the absence of SHP-1, NK cells are hyporesponsive in vitro and in vivo. We also show that SHP-1 is a major mediator of the inhibitory function of MHC class I-specific receptors. Thus, SHP1 governs the tuning of $\mathrm{NK}$ cells, and the inhibitory function of $\mathrm{MHC}$ class I-specific receptors is associated with their role in NK cell education.

\section{Results}

Deletion of SHP-1 in NK cells. We used Ncr $1^{i \mathrm{Cre} /}+$ mice $^{29}$ to eliminate SHP-1 selectively from NK cells and NKp46 ${ }^{+}$ILCs (also called $\mathrm{NCR}^{+}$ILC3) by crossing with knock-in mice in which the first nine exons of the gene encoding SHP-1 (Ptpn6) had been floxed ${ }^{30}$ (Supplementary Fig. 1). Unlike motheaten mice, which present a phenotype of massive inflammation leading to premature death, $N c r 1^{\text {iCre }}{ }^{+} \operatorname{Ptpn} 6^{\mathrm{flx} / \mathrm{flx}}$ mice were obtained at Mendelian frequencies; they developed normally and were fertile. No statistically significant differences in the numbers and percentages of cells of the lymphoid and myeloid subsets were detected by flow cytometry analyses of the blood, spleen and liver cells from $N c r 1^{\mathrm{iCre} /+}$ Ptpn $6^{+/+}$mice and $N c r 1^{\mathrm{iCre} /+}$ Ptpn $6^{\mathrm{flx} / \mathrm{flx}}$ mice (Fig. 1a and Supplementary Fig. 2). In particular, splenic $\mathrm{CD}^{-}{ }^{-} \mathrm{NKp}_{4} 6^{+} \mathrm{NK}$ cell counts were $3.5 \pm 1.2 \times 10^{6}$ (mean \pm s.d., $n=16)$ in $N c r 1^{\mathrm{iCre} /+} \operatorname{Ptpn} 6^{+/+}$mice and $3.6 \pm 1.4 \times 10^{6}$ in

Figure 1 | Deletion of SHP-1 in NK cells. (a) Left panels: representative cytometric profiles of splenocytes from $\mathrm{Ncri}^{\mathrm{iCre} /+}+\mathrm{Ptpn6}+/+$ and

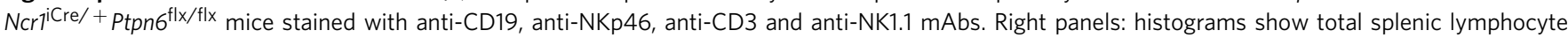
counts $(n=17, P=0.7554)$, percentages of CD3 ${ }^{+}$T cells $(n=17, P=0.5570), C_{19}{ }^{+}$B cells $(n=9, P=0.5346)$ and CD3 ${ }^{-}$NK1.1 ${ }^{+}$NK cells $(n=17$, $P=0.3046)$. Statistics were performed using a Mann-Whitney test. (b) Left panels: representative cytometric profiles of CD3 ${ }^{-}$gut lymphocytes from Ncri ${ }^{\mathrm{iCre} /+}$ Ptpn6 ${ }^{+/+}$and Ncri ${ }^{\mathrm{iCre} /+}+$ Ptpn $6^{\mathrm{flx} / \mathrm{flx}}$ mice stained with anti-NKp46 and anti-ROR $\gamma \mathrm{t}$ mAbs. Right panels: histograms show total gut lymphocyte counts $\left(n=9, P=0.2864\right.$, Mann-Whitney) and percentages of NK (CD3 $\left.{ }^{-} \mathrm{NKp}^{+} 6^{+} \mathrm{ROR}_{\mathrm{t}}{ }^{+}\right), \mathrm{NKp}^{-} 6^{-} \mathrm{ILC3}\left(\mathrm{CD}^{-} \mathrm{NKp}^{-} 6^{-} \mathrm{ROR}_{\mathrm{t}}{ }^{+}\right)$and NKp46 ${ }^{+}$ILC3 $\left(C D 3^{-} \mathrm{NKp} 6^{+} \mathrm{ROR}_{\mathrm{t}}{ }^{+}\right)$cells $(n=9, P>0.9999$, two-way analysis of variance (ANOVA) with Bonferroni correction). (c) Left panels:

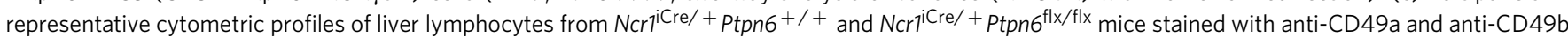
mAbs. Right panels: histograms show total liver lymphocyte counts $\left(n=15, P=0.6118\right.$, Mann-Whitney) and percentages of liver $\mathrm{CD}_{49} \mathrm{a}^{-} \mathrm{CD} 49 \mathrm{~b}^{+}$and $\mathrm{CD} 49 \mathrm{a}^{+} \mathrm{CD} 49 \mathrm{~b}^{-}$cells $(n=10, P>0.9999$, two-way ANOVA with Bonferroni correction). Each dot on the histograms corresponds to the data for a single mouse. The data show the results of at least four independent experiments. (d) Analysis of SHP-1 protein expression by immunoblotting in NK-depleted splenocytes (left panel) and LAK cells (right panel) prepared from the indicated mice. Representative of three independent experiments. 
$N c r 1^{\mathrm{iCre} /+}$ Ptpn $6^{\mathrm{flx} / \mathrm{flx}}$ mice (Fig. 1a). NK cell and $\mathrm{NCR}^{+}$ILC3 cell numbers were also normal in the small intestine of Ncr $1^{i C r e /+}$ Ptpn $6^{f l x / f l x}$ mice (Fig. 1b), and CD49a ${ }^{-} \mathrm{CD}_{4} 9 \mathrm{~b}^{+} \mathrm{NK}$ cells and tissue-resident $\mathrm{CD} 49 \mathrm{a}^{+} \mathrm{CD} 49 \mathrm{~b}^{-} \mathrm{NK}$ cells were present in normal numbers in the liver (Fig. 1c). The presence of NK cells in $N c r 1^{\text {iCre/ }+} \operatorname{Ptpn} 6^{\mathrm{flx} / \mathrm{flx}}$ mice made it possible for us to check a
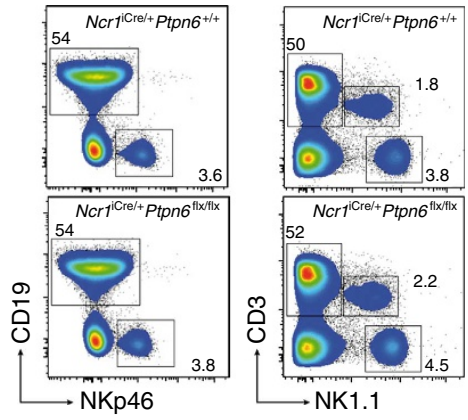

b
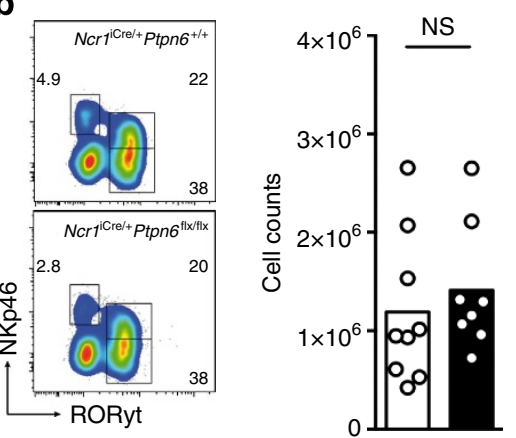

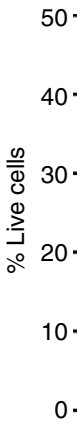

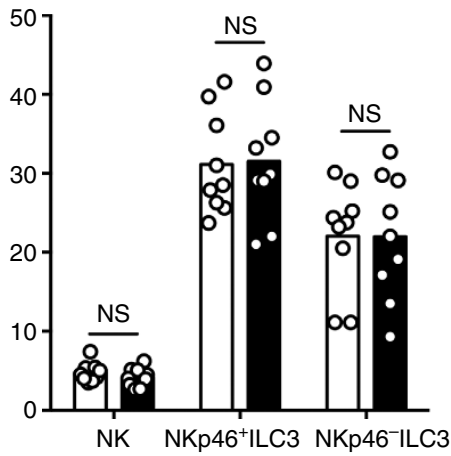

C
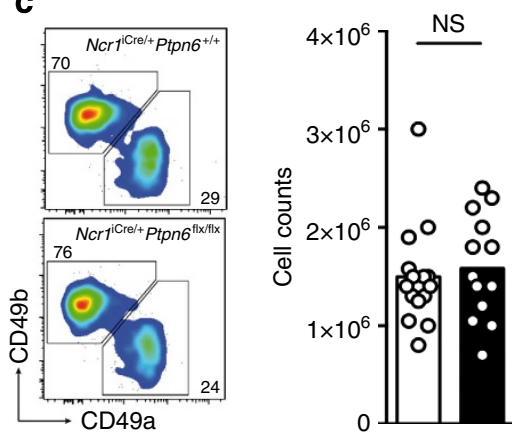
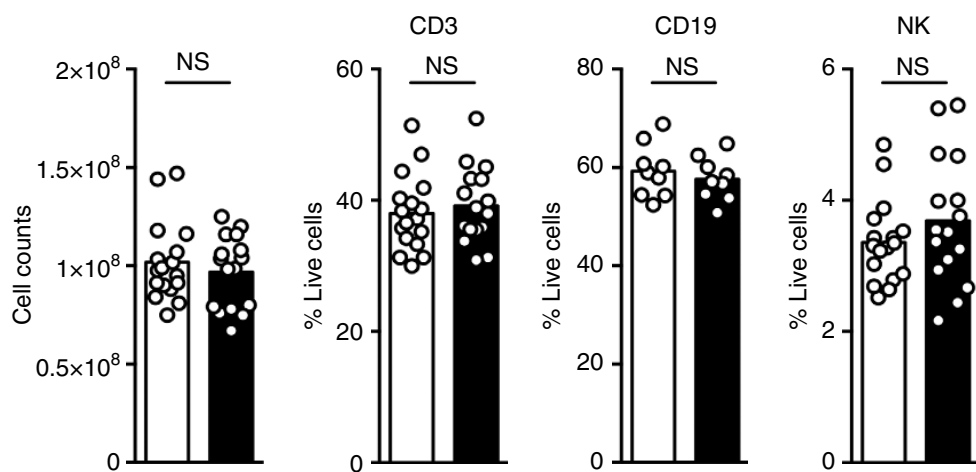

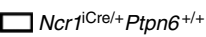

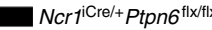

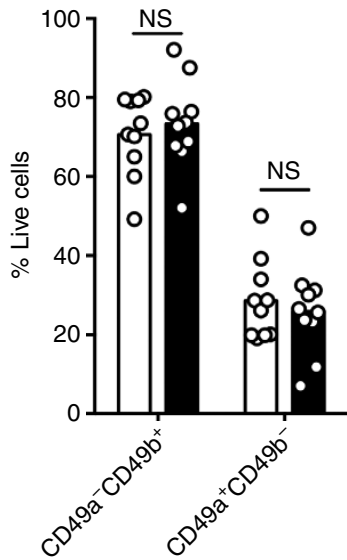

d

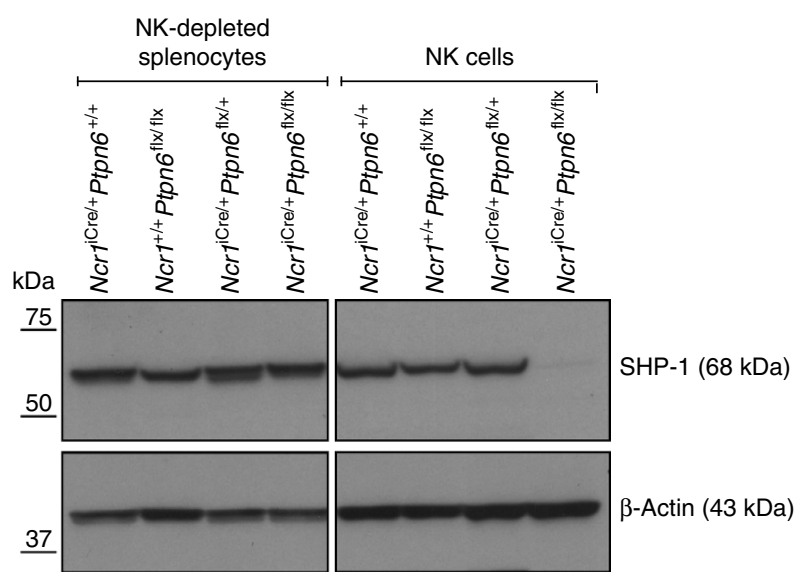


that SHP-1 was depleted selectively from NK cells and not from other splenocytes. In $N c r 1^{\text {iCre/ }+P t p n} 6^{\mathrm{flx} / \mathrm{flx}}$ mice, the SHP-1 protein was indeed undetectable in NK cells, but was present in other splenocytes (Fig. 1d and Supplementary Fig. 3), consistent with both the specificity of $N c r 1^{\text {iCre }}+$ targeting $^{29}$ and the efficacy of SHP-1 ablation observed in B cells ${ }^{32}$, T cells ${ }^{33}$, dendritic cells and neutrophils ${ }^{34}$ when Ptpn $6^{\mathrm{fx} / \mathrm{flx}}$ mice were crossed with other Cre knock-in mice. The elimination of SHP-1 from $\mathrm{NKp} 46^{+}$ cells therefore led to no gross abnormalities in the development of these cells and no massive inflammatory disease was observed in $N c r 1^{\text {iCre } /+} \operatorname{Ptpn} 6^{\mathrm{fx} / \mathrm{flx}}$ mice. This made it possible to carry out an unprecedented dissection of the functional consequences of an absence of SHP-1 in NK cells.

Changes to NK cell surface phenotype in absence of SHP-1. We investigated the impact of a lack of SHP-1 on the various stages of NK cell maturation. The absence of SHP-1 from NK cells resulted in moderate changes to the maturation profile of these cells, as shown by the higher proportion of $\mathrm{CD} 11 \mathrm{~b}^{+} \mathrm{CD} 27^{+} \mathrm{NK}$ cells and the corresponding lower proportion of $\mathrm{CD} 11 \mathrm{~b}^{+} \mathrm{CD} 27^{-}$cells in $N c r 1^{\text {iCrel }+}$ Ptpn $6^{\mathrm{fx} / \mathrm{flx}}$ mice than in $\mathrm{Ncr} \mathrm{I}^{\mathrm{iCre} /+} \mathrm{Ptpn}^{+/+}$control mice (Fig. 2a). The KLRG1 ${ }^{+}$splenic NK cell subset population was much smaller in $N c r 1^{\mathrm{iCre} /+} \operatorname{Ptpn} 6^{\mathrm{flx} / \mathrm{flx}}$ mice than in control mice (Fig. 2b). KLRG1 is a cell surface receptor, the extracytoplasmic domain of which interacts with cadherins, whereas the intracytoplasmic ITIM recruits the SHIP-1 inositol phosphatase $^{31}$. The biological relevance of KLRG1 expression on NK cells in vivo remains unclear ${ }^{32}$, but KLRG1 is preferentially expressed on mature $\mathrm{CD} 11 \mathrm{~b}^{+} \mathrm{CD} 27^{-} \mathrm{NK}$ cells ${ }^{33}$. The lower proportion of $\mathrm{CD} 11 \mathrm{~b}^{+} \mathrm{CD} 27^{-}$cells in $\mathrm{Ncr} 1^{\mathrm{iCre} /+}{ }^{\mathrm{Ptp}} n 6^{\mathrm{flx} / \mathrm{flx}}$ mice could not account for the weaker KLRG-1 expression in these mice, as the fraction of $\mathrm{KLRG}^{+}{ }^{+}$cells among $\mathrm{CD} 11 \mathrm{~b}^{+} \mathrm{CD}^{+} 7^{-} \mathrm{NK}$ cells was also lower (Supplementary Fig. 4). Similar observations were made for NK cells isolated from the liver (Supplementary Fig. 5), highlighting the impact of SHP-1 on KLRG1 expression. A similar decrease in the size of the $\mathrm{KLRG}^{+} \mathrm{NK}$ cell subset regardless of CD11bCD27 maturation phenotype has been consistently observed in MHC class I-deficient mice ${ }^{34}$ (Supplementary Fig. 6).

Skewing of Ly49 receptor repertoire in the absence of SHP-1. The absence of SHP-1 in NK cells had a marked effect on the expression of inhibitory Ly49 receptors. The NK cell subsets expressing Ly49A, Ly49C/I, Ly49F or Ly49G2 were larger in $N c r 1^{\text {iCre/ }+}$ Ptpn $6^{\mathrm{flx} / \mathrm{flx}}$ mice than in $N c r 1^{\mathrm{iCre}^{\mathrm{CH}}+\mathrm{Ptpn}^{+/+} \text {control }}$ mice (Fig. 3a). This effect was specific to the inhibitory Ly49 receptors, as no change in the expression of the activating Ly49D and Ly49H receptors, NKG2A or NKG2D, was observed in the absence of SHP-1 (Fig. 3b). Similarly, the repertoire of inhibitory Ly49 receptors, but not of activating Ly49 receptors, is altered in MHC class I-deficient mice ${ }^{35,36}$ (Supplementary Fig. 7a,b). Thus, two major features of NK cells in MHC class I-deficient mice-low levels of KLRG1 expression and high levels of expression of the inhibitory Ly49 receptors-were found in $N c r 1^{\mathrm{iCre} /+} \operatorname{Ptpn} 6^{\mathrm{flx} / \mathrm{flx}}$ mice.

In vitro NK cell hyporesponsiveness in the absence of SHP-1. We then investigated the reactivity of $\mathrm{NK}$ cells in $\mathrm{Ncrl} \mathrm{I}^{\mathrm{iCre} /+}$ $P t p n 6^{f l x} / f \mathrm{~lx}$ mice, comparing it with that of NK cells from Ncr $1^{\text {iCre } /+}$ Ptpn $6^{+/+}$mice. Splenic NK cells were cultured in vitro with interleukin (IL)-2 to generate lymphocyte-activated killer (LAK) cells. The proliferative response of NK cells to IL-2 was unaffected by the absence of SHP-1 (Fig. 4a). By contrast, $N c r 1^{\text {iCrel }+P t p n} 6^{\mathrm{fx} / \mathrm{flx}}$ LAK cells were unable to secrete IFN- $\gamma$ in the presence of YAC tumour cells (Fig. 4b). In addition, the ability of LAK cells from Ncr $1^{\text {iCre/ }+P t p n} 6^{\mathrm{flx} / \mathrm{flx}}$ mice to kill YAC, a
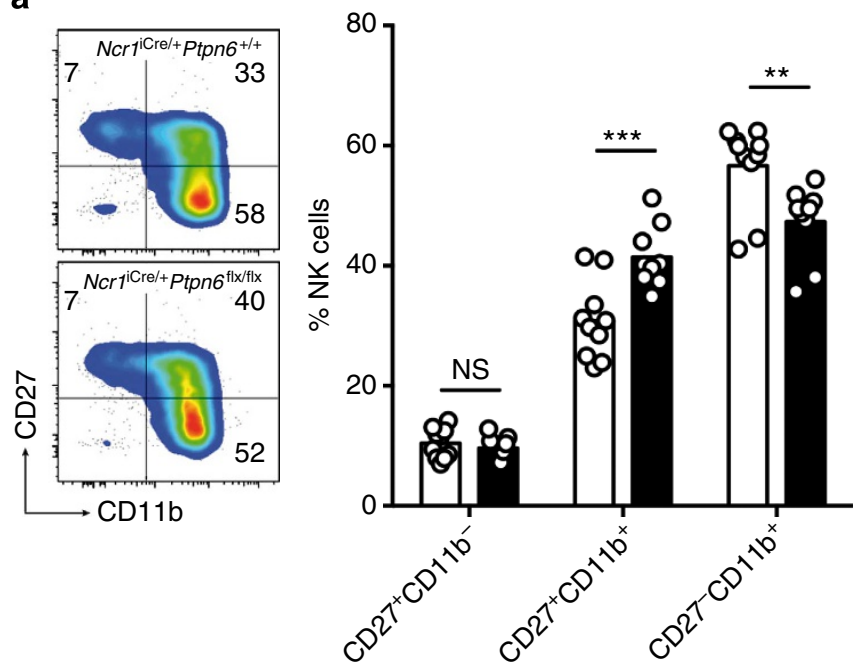

b
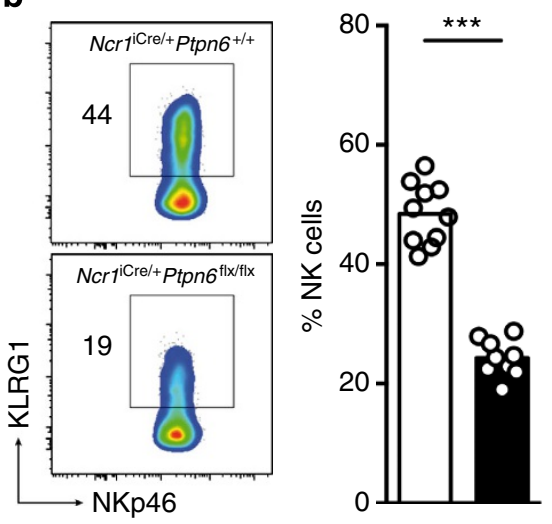

Figure 2 | Alteration of NK cell surface phenotype in the absence of SHP-1. (a) Left panel: representative cytometric profiles of splenic NK cells stained with anti-CD27 and anti-CD11b mAbs. Right panel: histograms show the percentages of $\mathrm{CD} 27{ }^{+} \mathrm{CD}_{11 \mathrm{~b}}-(P>0.9999), \mathrm{CD} 27^{+} \mathrm{CD} 11 \mathrm{~b}+$ $(P=0.0002)$ and $\mathrm{CD}_{27}{ }^{-} \mathrm{CD} 11 \mathrm{~b}{ }^{+}(P=0.0011) \mathrm{NK}$ cells. $(n=10$, two-way analysis of variance with Bonferroni correction). (b) Left panel: representative cytometric profiles of splenic NK cells stained with antiKLRG1 and anti-NKp46 mAbs. Right panel: histograms show the percentages of $\mathrm{KLRG}^{+}{ }^{+} \mathrm{NK}$ cells from Ncri $7^{\mathrm{iCre} /+}+\mathrm{Ptpn}^{+/+}$and $N c r 1^{i C r e /+P t p n} 6^{f \mid x / f l x}$ mice $(n=10, P<0.0001$, Mann-Whitney). Each dot on the histograms corresponds to the data for a single mouse and the data show the results of four independent experiments.

RMA-S and RMA-Rae1 tumour cells in vitro was profoundly compromised (Fig. 4c). Thus, an absence of SHP-1 from NK cells decreased their cytotoxic and cytokine effector activities in response to tumour cells in vitro.

Early signalling in NK cells in the absence of SHP-1. We then sought to dissect the mechanisms of the in vitro NK cell hyporeactivity in $N c r 1^{\mathrm{iCre} /+} \mathrm{Ptpn} 6^{\mathrm{flx} / \mathrm{flx}}$ mice, by investigating the extent to which the absence of SHP-1 in NK cells controlled the early signalling events induced by the engagement of activating receptors. We focused on quantitative measurements of the two major signalling pathways: the generation of phosphatidylinositol trisphosphates (PtdIns $\left.(3,4,5) P_{3}\right)$ and intracytoplasmic $\mathrm{Ca}^{2+}$ $\left(\mathrm{iCa}^{2+}\right)$ mobilization.

The cytoplasmic membrane is composed of phosphatidylinositol phosphate $(\operatorname{PtdIns}(4) P)$, bisphosphates $\left(\operatorname{PtdIns}(4,5) P_{2}\right)$ and a 
a
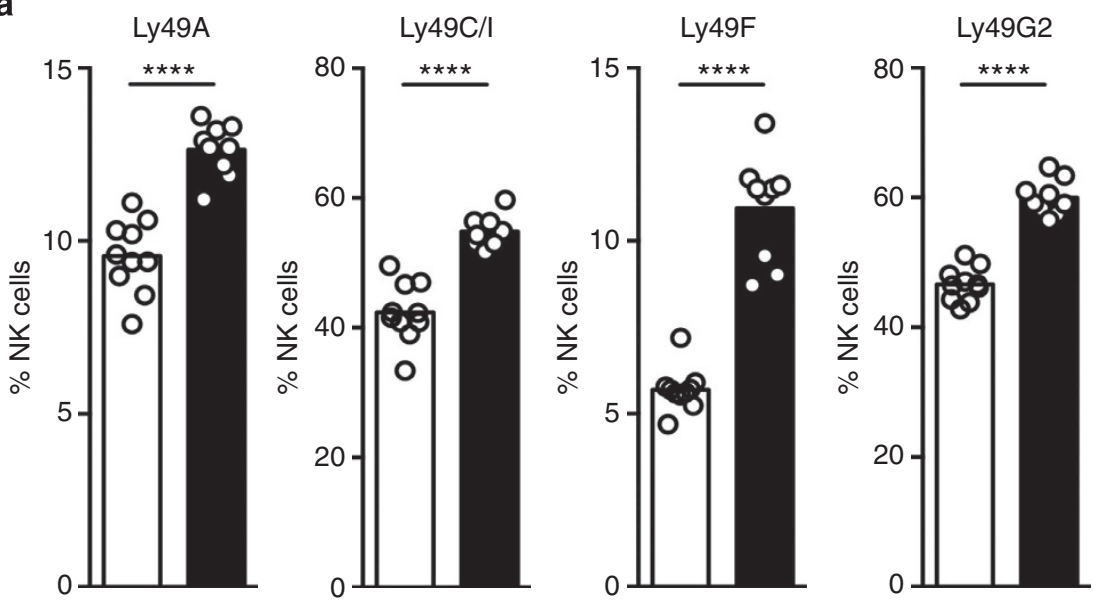

b
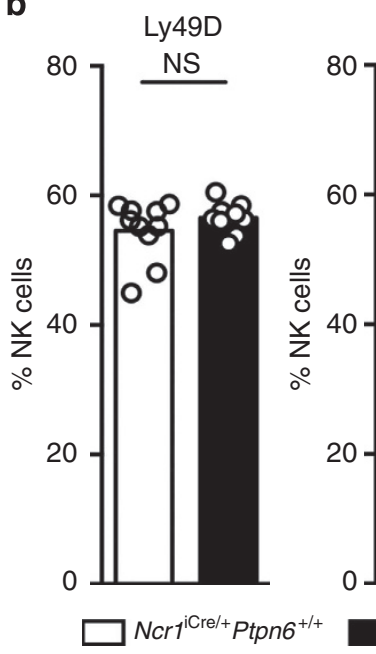

Ly49H
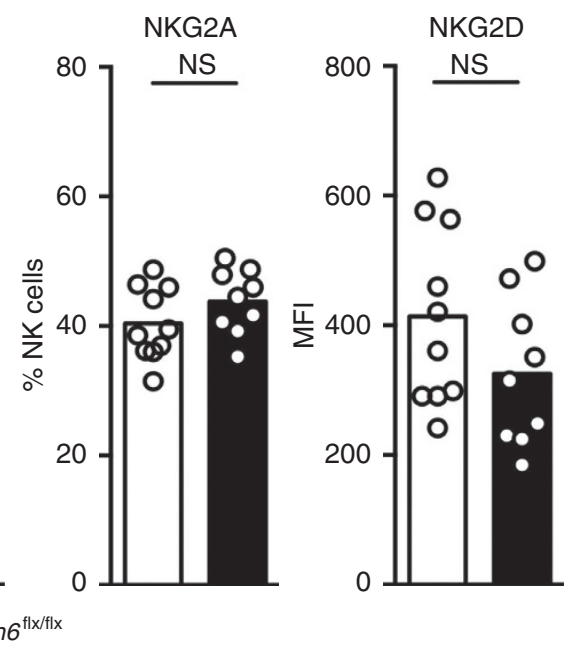

Figure 3 | Skewing of Ly49 receptor repertoire in the absence of SHP-1. (a) Percentages of NK cells expressing cell surface Ly49 inhibitory receptors

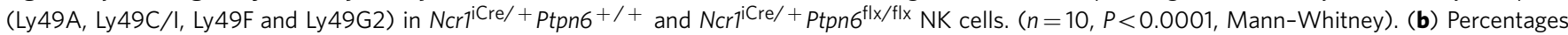
of NK cells expressing cell surface the NKG2A $(P=0.1894)$ inhibitory receptor or Ly49 activating receptors (Ly $49 \mathrm{D}, P=0.5633$ and Ly $49 \mathrm{H}$,

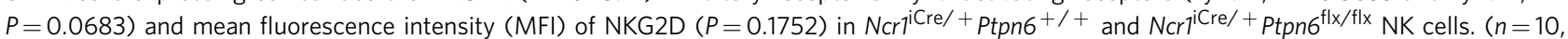

Mann-Whitney). Each dot on the histograms corresponds to the data from a single mouse and the data show the results of four independent experiments.

lower proportion of $\operatorname{PtdIns}(3,4,5) P_{3}$. Using a recently described highly sensitive mass spectrometry method ${ }^{37}$, we quantified the basal amounts of PtdIns(4)P, PtdIns $(4,5) P_{2}$ (Supplementary Fig. 8) and the various molecular species of $\operatorname{PtdIns}(3,4,5) P_{3}$ differing in terms of acyl chain composition (C18:0/C18:0, C18:0/ C18:1, C18:0/C18:2, C18:0/C20:2, C18:0/C20:3 and C18:0/C20:4) (Fig. 5a). Ncr $1^{\mathrm{iCre} /+} \mathrm{Ptpn}^{+1+}$ and $\mathrm{Ncr} \mathrm{I}^{\mathrm{iCre} /+}+\mathrm{Ptpn}^{\mathrm{fl} / \mathrm{flx}}$ resting NK cells had similar basal levels of these different molecular species. Following their stimulation via Ly49D, control NK cells displayed a very early induction of C18:0/C20:3 and C18:0/C20:4 PtdIns $(3,4,5) P_{3}, \quad 1 \mathrm{~min}$ after cross-linking, followed by a decline after $5 \mathrm{~min}$ of stimulation (Fig. 5b). The quantity, quality and kinetics of the $\operatorname{PtdIns}(3,4,5) P_{3}$ generated did not differ significantly between NK cells isolated from $\mathrm{Ncr} \mathrm{i}^{\mathrm{iCre} /}+\mathrm{Ptpn}^{\mathrm{fl} \mathrm{x} / \mathrm{flx}}$ mice and NK cells isolated from $\mathrm{Ncr}^{\text {iCre/ }+}{ }^{\text {Ptpn }} 6^{+/+}$mice (Fig. 5a,b).

For the assessment of real-time $\mathrm{iCa}^{2+}$ mobilization, freshly isolated NK cells from $\mathrm{Ncr}^{1 \mathrm{Cre} /+}+\mathrm{Ptpn} 6^{\mathrm{flx} / \mathrm{flx}}$ and $\mathrm{Ncr} \mathrm{I}^{\mathrm{iCre} /+}$ $P \operatorname{tpn} 6^{+1+}$ control mice were incubated in vitro with biotinylated monoclonal antibodies (mAbs) against Ly49D or NKG2D. Antibody-coated NK cells were then incubated with streptavidin for the assessment of real-time $\mathrm{iCa}^{2+}$ mobilization by flow cytometry. Receptor-mediated $\mathrm{iCa}^{2+}$ mobilization was assessed by determining the intensity of the $\left[\mathrm{iCa}^{2+}\right]$ peak and the integration of $\left[\mathrm{iCa}^{2+}\right]$ over time. As expected, binding to Ly49D or NKG2D led to an increase in $\left[\mathrm{iCa}^{2+}\right]$ in NK cells from $N \mathrm{Nr} \mathrm{1}^{\mathrm{iCre} /+} \mathrm{Ptpn}^{+/+}$control mice (Fig. 6a). However, the peak of $\left[\mathrm{iCa}^{2+}\right]$ induced by Ly49D cross-linking was $\sim 40 \%$ lower in NK cells from $N c r 1^{1 \mathrm{Cre} /+} \operatorname{Ptpn} 6^{\text {flx/flx }}$ mice than in NK cells from $\mathrm{Ncrl}^{\mathrm{iCre} /+}{ }^{\mathrm{Ptpn} 6^{+/+}}$mice (Fig. 6a (upper panel) and b). Moreover, $\mathrm{iCa}^{2+}$ mobilization in the NK cells of $\mathrm{Ncrl}^{\mathrm{iCre} /+}$ $P t p n 6^{\mathrm{fl} / \mathrm{flx}}$ mice was $90 \%$ weaker after incubation with NKG2D mAbs (Fig. 6a (lower panel) and Fig. 6b). Similar results were obtained with $\beta 2 \mathrm{~m}^{-1}$ (Supplementary Fig. 9a,b) and, in both types of mice, no difference in $\mathrm{iCa}^{2+}$ mobilization was observed when NK cells were stimulated with ionomycin (Supplementary Fig. 9c). Thus, the hyporeactivity of NK cells intrinsically lacking SHP-1 primarily affects $\mathrm{iCa}^{2+}$ mobilization, but not generation of the second messenger PtdIns $(3,4,5) P_{3}$ induced by engagement of activating receptors.

SHP-1 is a major mediator of MHC class I receptors inhibition. Given the role of inhibitory MHC class I-specific receptors in NK cell tuning and the putative role of SHP-1 as an effector acting downstream from these inhibitory receptors, we assessed 

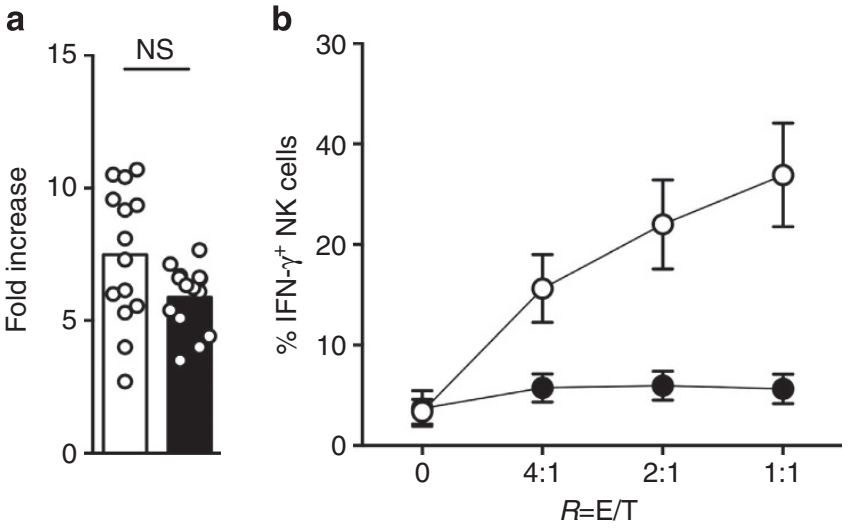

C
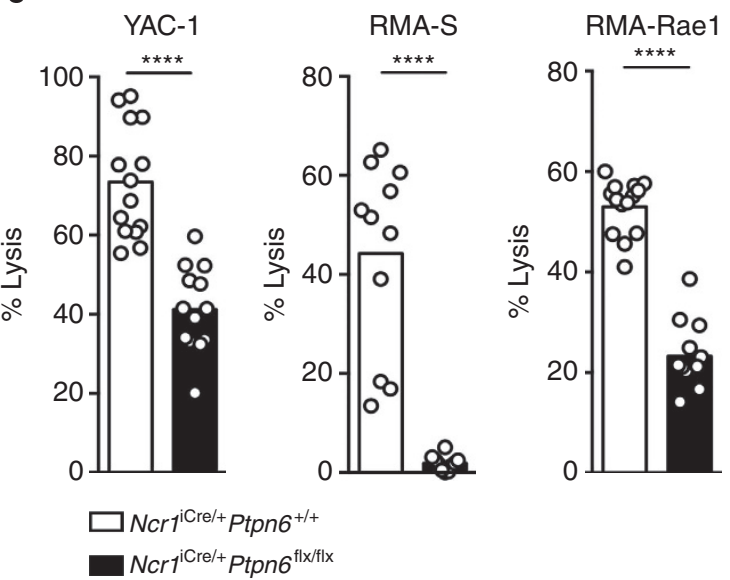

Figure 4 | In vitro NK cell hyporesponsiveness in the absence of SHP-1. (a) Fold-increase in NK cell numbers after 7 days of culture with IL-2 were obtained using a cell counter. ( $n=14, P=0.1164$, Mann-Whitney).

(b) Intracellular IFN- $\gamma$ production by LAK cells on stimulation with YAC-1 tumour cells was measured by intracellular cytokine staining. $(n=10$, $P<0.0001$, two-way analysis of variance with Bonferroni correction). (c) LAK cell lysis of the YAC-1 $(n=14)$, RMA-S $(n=11)$ and RMA-Rae1 $(n=4)$ cell lines measured in $\mathrm{Cr}^{51}$ release assay. $(P<0.0001$, MannWhitney). Each dot on the histograms corresponds to the data from a single mouse $(\mathbf{a}, \mathbf{c})$ or the mean of several experiments $(\mathbf{b})$; the data show the results of at least three independent experiments.

the impact of the lack of SHP-1 on the function of the MHC class I-specific receptors expressed on NK cells. The percentages of NK cells expressing inhibitory Ly49 receptors differed between $N c r 1^{\text {iCrel }+}$ Ptpn $6^{\text {flx/flx }}$ and $N c r 1^{\text {iCre/ }+}$ Ptpn $6^{+/+}$mice (Fig. 3a). We therefore first focused on inhibitory CD94/NKG2A heterodimers and activating Ly49D receptors, the expression of which was not affected by the lack of SHP-1 in NK cells (Fig. 3b). The inhibitory function of ITIM-bearing molecules is dependent on their co-aggregation with activating receptors ${ }^{21}$. In NK cells, only activating receptors stimulated together with MHC class I-specific inhibitory receptors are affected, displaying lower levels of activation, whereas other activating receptors not co-engaged with inhibitory receptors are unaffected ${ }^{21}$. Freshly isolated NK cells from Ncr $1^{\text {iCre/ }+P t p n} 6^{\mathrm{flx} / \mathrm{flx}}$ and $N c r 1^{\text {iCrel }}$ ${ }^{+}$Ptpn $6^{+/+}$control mice were thus incubated in vitro with biotinylated Ly49D mAbs in the presence or absence of biotinylated NKG2A mAbs, and real-time $\mathrm{iCa}^{2}+$ mobilization was measured. In $\mathrm{Ncr} \mathrm{I}^{\mathrm{iCre} /+} \mathrm{Ptpn}^{+/+}$control mice, binding to Ly49D led to an increase in $\left[\mathrm{iCa}^{2+}\right.$, which was $\sim 40 \%$ smaller if the CD94/NKG2A molecules were co-engaged (Fig. 7a (upper panel) and b). By contrast, almost no inhibition of Ly49Dinduced $\mathrm{iCa}^{2}+$ fluxes was observed when CD94/NKG2A molecules were co-engaged in $N c r 1^{\mathrm{iCre} /+} \operatorname{Ptpn} 6^{\mathrm{flx} / \mathrm{flx}}$ mice (Fig. 7a (lower panel) and b). The co-engagement of NKG2A and Ly49D impaired Ly49D-induced $\mathrm{iCa}^{2}+$ mobilization in NK cells isolated from $\beta 2 \mathrm{~m}^{-I-}$ mice, ruling out the possibility that the lack of inhibition of CD94/NKG2A heterodimers in $N c r 1^{\text {iCre/ }+}$ Ptpn $6^{\text {flx/flx }}$ NK cells was due to their hyporeactivity (Supplementary Fig. 10).

For precise quantification of the inhibitory function of $\mathrm{H}-2 \mathrm{~K}^{\mathrm{b}}$ specific Ly49C/I molecules in the absence of SHP-1, we compared NK cells isolated from $\beta 2 \mathrm{~m}^{-1-}$ mice and $N c r 1^{\mathrm{iCre} /+} \mathrm{Ptpn} 6^{\mathrm{flx} / \mathrm{flx}}$ mice, as these two types of mice had similar Ly49C/I cell percentages (Fig. 3a and Supplementary Fig. 7a). In $\beta 2 \mathrm{~m}^{-1-}$ mice, Ly49C/I inhibited Ly49D-mediated $\mathrm{iCa}^{2}+$ mobilization by $\sim 65 \%$ (Fig. $7 c$ (upper panel) and Fig. 7d), consistent with the high percentage of Ly49C/I cells in these mice. By contrast, the inhibitory function of Ly49C/I was strongly impaired in $N c r 1^{\text {iCre/ }+}$ Ptpn $6^{\text {flx } / \mathrm{flx}}$ mice (Fig. 7c (lower panel) and Fig. $7 \mathrm{~d}$ ). Thus, the absence of SHP-1 from NK cells impaired the inhibition mediated by Ly49C/I and CD94/NKG2A heterodimers, identifying SHP-1 as a major mediator of their inhibitory function in mouse NK cells.

In vivo NK cell hyporesponsiveness in the absence of SHP-1. We then analysed the in vivo consequences of the in vitro hyporeactivity of NK cells lacking SHP-1. Control and $N c r 1^{\text {iCre } /+}$ Ptpn $6^{\text {flx/flx }}$ mice received injections of a 1:1 mixture of wild-type and $\beta 2 \mathrm{~m}^{-/-}$splenocytes, in a standard in vivo missing-self-recognition assay ${ }^{13,38,39}$. As expected, control mice rejected $\beta 2 \mathrm{~m}^{-/-}$splenocytes (Fig. 8a) due to the lack of engagement of inhibitory MHC class I receptors on recipient NK cells by $\beta 2 \mathrm{~m}^{-/-}$splenocytes. By contrast, Ncr $1^{\mathrm{iCre} /+}$ Ptpn $6^{\mathrm{flx} / \mathrm{flx}}$ mice were unable to reject $\beta 2 \mathrm{~m}^{-/-}$splenocytes (Fig. 8a). Thus, NK cells from $N c r 1^{\mathrm{iCre} /}+P t p n 6^{\mathrm{flx} / \mathrm{flx}}$ mice cannot eliminate MHC class I-deficient cells in vivo.

We also injected luciferase ${ }^{+}$B16 melanoma cells intravenously into $\mathrm{Ncr} 1^{\mathrm{iCre} /+} \mathrm{Ptpn} 6^{\mathrm{flx} / \mathrm{flx}}$ or control $\mathrm{Ncr} 1^{\mathrm{iCre} /+} \mathrm{Ptpn}^{+/+}$mice and assessed tumour growth over time by bioluminescence imaging. The development of B16 melanoma cells in vivo is known to be controlled by NK cells (Supplementary Fig. 11) ${ }^{40}$. By contrast to what was observed for $N c r 1^{\text {iCre/ }+}$ Ptpn $^{+/+}$ mice, massive B16 tumour development was observed in $N c r 1^{\mathrm{iCre} /+}$ Ptpn $6^{\mathrm{flx} / \mathrm{flx}}$ mice (Fig. 8b). Ncr $1^{\text {iCre/ }+}$ Ptpn $6^{\mathrm{flx} / \mathrm{flx}} \mathrm{NK}$ cells thus display a marked hyporeactivity in vivo, characterized by their inability to reject MHC class I-deficient haematopoietic cells and B16 melanoma tumours.

\section{Discussion}

We describe here the impact of an intrinsic lack of SHP-1 in mouse NK cells. Unlike other immune cells, such as B cells ${ }^{30}$, $\mathrm{CD}^{+} \mathrm{T}$ cells ${ }^{41}$, regulatory $\mathrm{T}$ cells ${ }^{42}$, dendritic cells and neutrophils $^{43}$, we show here that SHP-1-deficient NK cells are hyporesponsive and do not promote inflammation or autoimmunity. NK cells are, to our knowledge, the only cell type in which a lack of SHP-1 increases, rather than decreases, the activation threshold. Indeed, we show that SHP-1 expression in $\mathrm{NK}$ cells is required for their functional competence. In the absence of SHP-1, NK cells were present, but their phenotype resembled that of NK cells from MHC class I-deficient hosts, with impaired KLRG-1 expression, a skewing of the repertoire of inhibitory Ly 49 receptors and a hyporesponsiveness of NK cells to various tumours and to MHC class I-negative haematopoietic grafts. Ly49 knockdown mice $\left(\mathrm{NKC}^{\mathrm{KD}}\right)$ also present some of these features, as they are also hyporesponsive in vivo to $\mathrm{MHC}$ 

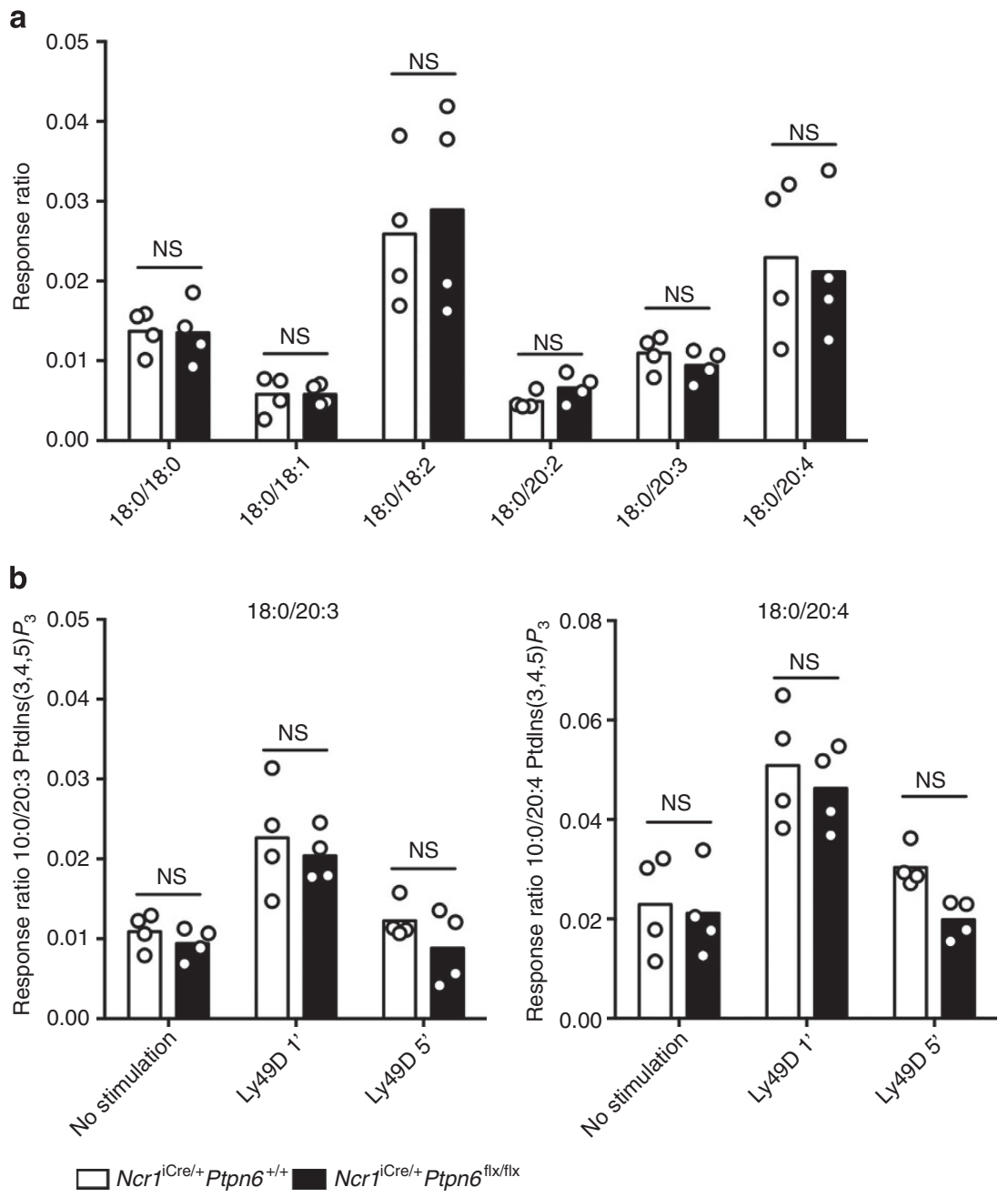

Figure 5 | Generation of Ptdins $(\mathbf{3}, \mathbf{4}, \mathbf{5}) \mathbf{P}_{\mathbf{3}}$ molecular species induced by NK cell activation in the absence of SHP-1. (a) The basal amounts of the

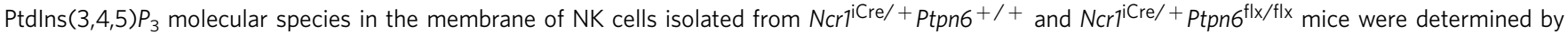
mass spectrometry. $(n=4, P>0.9999$, two-way analysis of variance (ANOVA) with Bonferroni correction.) (b) The amounts of C18:0/C20:3 and C18:0/C20:4 Ptdlns $(3,4,5) P_{3}$ molecular species were determined after $1(P>0.9999)$ or 5 min $(18: 0 / 20: 3, P=0.7407$ and 18:0/20:4, $P=0.2894)$ of activation with anti-Ly49D mAbs cross-linked to with $\mathrm{F}(\mathrm{ab})^{\prime} 2 \mathrm{mAbs}$. The other molecular species of Ptdlns $(3,4,5) P_{3}$ did not change significantly following stimulation. ( $n=4$, two-way ANOVA with Bonferroni correction). Data are expressed as response ratio (integrated ion current response to the defined Ptdlns $(3,4,5) P_{3}$ molecular species divided by that to the internal standard) ${ }^{45}$. Each dot on the histograms corresponds to the data for a NK cell preparation from a pool of four mice and the data show the results of two independent experiments.

class I-negative haematopoietic grafts and tumours ${ }^{18}$. Many receptors and pathways are regulated by SHP-1 in lymphocytes, including NK cells ${ }^{44}$. The similarity of the phenotypes associated with an absence of SHP-1 and an absence of MHC class I receptor engagement strongly suggests that SHP-1 is used principally by Ly49 and NKG2A in NK cells. Our findings are consistent with the NK cell hyporesponsiveness induced by the transdominant negative form of SHP-1, although the alteration in NK cell function was less pronounced, probably due to the partial impairment of SHP-1 function in this experimental model ${ }^{27}$.

A paradox thus remains to be resolved: how can the lack of a protein tyrosine phosphatase that downregulates NK cell activation when recruited by inhibitory receptors lead to NK cell hyporesponsiveness rather than hyperactivation, as in other lymphocytes? Our dissection of the mechanisms underlying NK cell tuning by MHC class I receptors was based on two aspects. First, in the absence of SHP-1, the inhibitory function of MHC class I receptors (CD94/NKG2A heterodimers and Ly49C/I receptors) was barely detectable. Thus, although ITIM-bearing MHC class I receptors can bind SHP-2 (refs 21,22) or be linked to
Crk phosphorylation ${ }^{24}$, our data indicate that SHP-1 is a key signalling molecule for the inhibitory function of MHC class I receptors in mouse NK cells. These findings are consistent with those for the silencing of Ptpn6, which results in an inability of ITIM-bearing inhibitory receptors to prevent the activation of mouse primary $\mathrm{NK}$ cells ${ }^{45}$. Second, we found that the intrinsic lack of inhibitory MHC class I receptor function was linked to NK cell hyporesponsiveness. Thus, our data are consistent with a model in which, in the absence of MHC class I detection, NK cells are desensitized due to their unrestrained activation by the chronic recognition of endogenous stimulating ligands in vivo, that is, the disarming model ${ }^{14}$. The induction of cell desensitization by the sustained activation of signalling elements is a very common mechanism that has been conserved throughout evolution. NK cells are innate lymphocytes expressing a wide panel of activating receptors, cytokine receptors and adhesion molecules ${ }^{2}$. Some of the ligands of these activating receptors are induced by various forms of cellular stress, ranging from microbial infection to tumour transformation, but other ligands are expressed constitutively in steady-state conditions in 
a

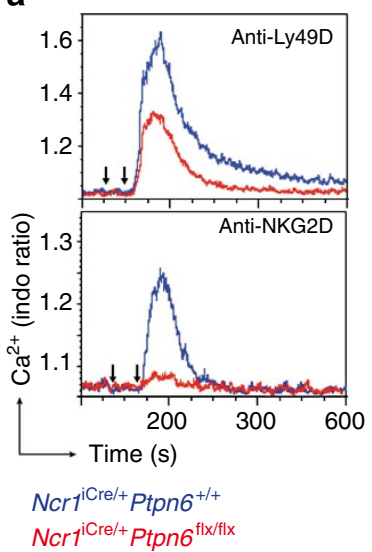

b

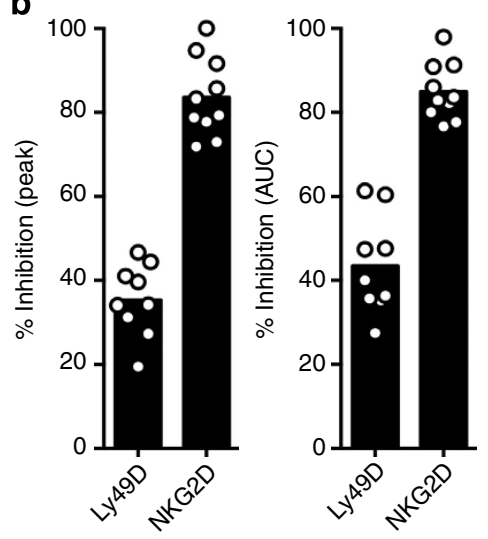

a

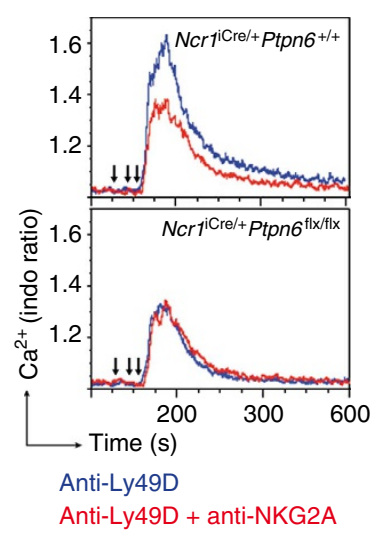

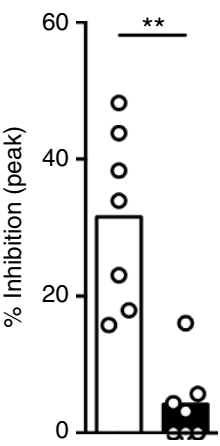

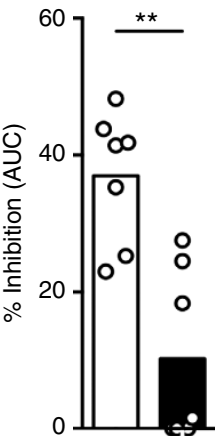

$\square \mathrm{Ncr}^{1 \mathrm{Cr} e /+}$ Ptpn6 ${ }^{+/+} \square \mathrm{Ncr} 1^{\mathrm{iCre} /+} \mathrm{Ptpn} 6^{\mathrm{fl|} / \mathrm{fl} \mathrm{x}}$

Figure 6 | $\mathrm{iCa}^{2}+$ mobilization induced by NK cell activation in the absence of SHP-1. (a) $\mathrm{iCa}^{2}+$ mobilization in freshly isolated NK cells, measured by flow cytometry. Ncri $7^{\mathrm{C} r e /}+\mathrm{Ptpn}^{+/+}$(blue curve) and

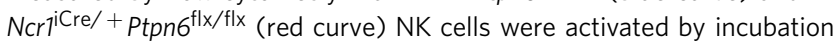
with biotinylated anti-Ly49D mAbs (first arrow, above) or biotinylated antiNKG2D mAbs (first arrow, below), which were cross-linked with streptavidin $30 \mathrm{~s}$ later (second arrow). (b) Peak $\mathrm{iCa}^{2}+$ mobilization and the area under the curve (AUC) are indicated as a \% inhibition in

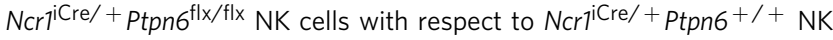
cells. (Ly49D, $n=9$; NKG2D, $n=10$ ). Each dot on the histograms corresponds to the data for a NK cell preparation from a pool of four mice and the data show the results of three independent experiments.

healthy organisms. This is the case for adhesion molecules, SLAM-family members, Nectin-like molecules and cytokines, such as IL-15 (refs 46,47). Thus, NK cells can respond to many endogenous ligands, at all stages of development. This high likelihood of NK cell activation by endogenous ligands contrasts with that of $\mathrm{T}$ and $\mathrm{B}$ cells, which is much lower due to a combination of the clonal organization of their responses and the selection and specificity of their antigen receptor repertoires. Our model of NK cell desensitization is supported by previous studies, in which the chronic expression of ligands for activating NK cell receptors was found to lead to NK cell hyporesponsiveness in vitro and in vivo ${ }^{48-51}$. It has also been described in humans, for NK cells expressing the activating KIR2S1 receptors in individuals bearing the cognate HLA-C2 group molecules ${ }^{52}$. As an alternative to the model of NK cell desensitization, it could be proposed that the lack of inhibition results in a developmental block yielding $\mathrm{CD} 11 \mathrm{~b}^{+} \mathrm{CD} 27^{+} \mathrm{NK}$ cells that, in an attempt to acquire an inhibitory receptor, continue to accumulate inhibitory Ly49 receptor at their surface ${ }^{14}$. We do not favour this possibility as $N c r 1^{\text {iCre } /+}$ Ptpn $6^{\mathrm{fx} / \mathrm{flx}} \mathrm{NK}$ cells present only a moderate change in their maturation profile as judged by the cell surface expression of CD11b and CD27; however, further experiments would be required to fully exclude this possibility.

Which signalling components are affected by the sustained absence of SHP-1 activity in NK cells and which are involved in NK cell hyporesponsiveness? We focused our analysis on the signalling elements known to be targeted by SHP-1 and on the NKG2D- and Ly49D-dependent signalling pathways, which we showed to be impaired in SHP-1-deficient NK cells. SHP-1 can downregulate the activation of many signalling molecules, including Src family protein tyrosine kinases (SFKs), Vav1, SLP-76, phosphoinositide phospholipase C- $\gamma$ (PLC- $\gamma$ ) and phosphoinositide 3 -kinase $(\mathrm{PI} 3 \mathrm{~K})^{22,44,53}$. In resting mouse NK cells, NKG2D associates with DAP10 (ref. 54), triggering two signalling pathways. DAP10 activates a Grb2, Vav1, SLP-76

b

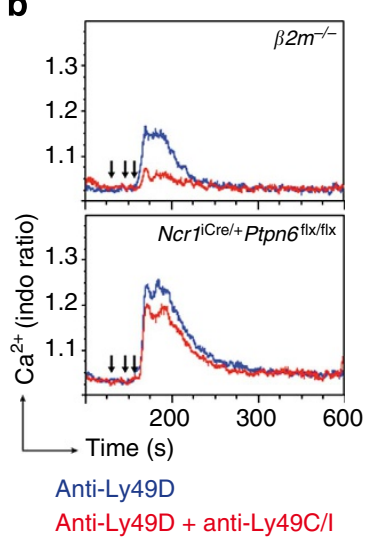

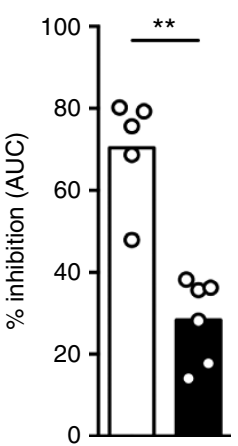

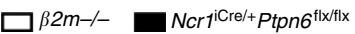

Figure 7 | SHP-1 is a major mediator of the inhibitory function of MHC class I-specific receptors. (a) $\mathrm{iCa}^{2+}$ mobilization in freshly isolated NK cells from $\mathrm{Ncr}^{\mathrm{iCre} /+}+\mathrm{Ptpn}^{+/+}$mice (above) or $\mathrm{Ncr} 7^{\mathrm{iCre} /+}+\mathrm{Ptpn}^{\mathrm{fl} / \mathrm{flx}}$ mice (below). Blue curve: NK cells were treated with biotinylated anti-Ly49D mAbs (second arrow). Red curve: other NK cell preparations were treated with biotinylated anti-NKG2A mAbs (first arrow) and then with biotinylated anti-Ly49D mAbs (second arrow). Biotinylated antibodies were cross-linked with streptavidin (third arrow). (b) Peak $\mathrm{iCa}^{2+}$ mobilization and the AUC for the indicated mice are indicated as a \% inhibition for NK cells stimulated via Ly49D and NKG2A with respect to NK cells stimulated via Ly49D alone. ( $n=7$, AUC $P=0.0041$ and peak $P=0.0012$, Mann-Whitney). (c) As in a, except that we used NK cells from $\beta 2 \mathrm{~m}^{-/-}$(upper panel) mice or $\mathrm{Ncr} 7^{\mathrm{iCre} /+}+\mathrm{Ptpn}^{\mathrm{fl} \times / \mathrm{flx}}$ mice (lower panel), and these cells were stimulated via Ly49D (blue curve) or Ly49D and Ly49C/I (red curve). (d) Peak iCa ${ }^{2+}$ mobilization and the AUC for the indicated mice are indicated as a \% inhibition for NK cells stimulated via Ly49D and Ly49C/I with respect to NK

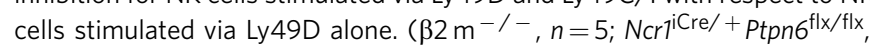
$n=6$; $A \cup C$ and peak $P=0.0043$, Mann-Whitney). Each dot on the histograms corresponds to the data for a NK cell preparation from a pool of four mice and the data the data show the results of two $(\mathbf{c}, \mathbf{d})$ or three $(\mathbf{a}, \mathbf{b})$ independent experiments.

signalosome, which in turn activates PLC- $\gamma$, leading to $\mathrm{iCa}^{2+}$ mobilization. It also activates $\mathrm{PI} 3 \mathrm{~K}^{55}$, leading to the generation of PtdIns $(3,4,5) P_{3}$ from PtdIns $(4,5) P_{2}$. Ly49D associates with the ITAM-bearing polypeptide DAP12, providing a link to the PLC- $\gamma$ and PI3K pathways ${ }^{53}$. Both $\mathrm{iCa}^{2+}$ mobilization and PtdIns $(3,4,5) P_{3}$ metabolites are essential for NK cell effector function $^{22,53,56}$. We observed no major effect of the lack of SHP-1 on the generation of different molecular species of $\operatorname{PtdIns}(3,4,5) P_{3}$ induced by NK cell activation, indicating that changes to the PI3K pathway play no major role in the NK cell hyporesponsiveness observed in $N c r 1^{\mathrm{iCre} /+} \operatorname{Ptpn} 6^{\mathrm{flx} / \mathrm{flx}}$ mice. By contrast, there are 
a

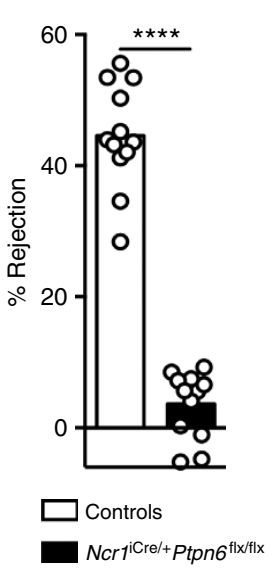

b

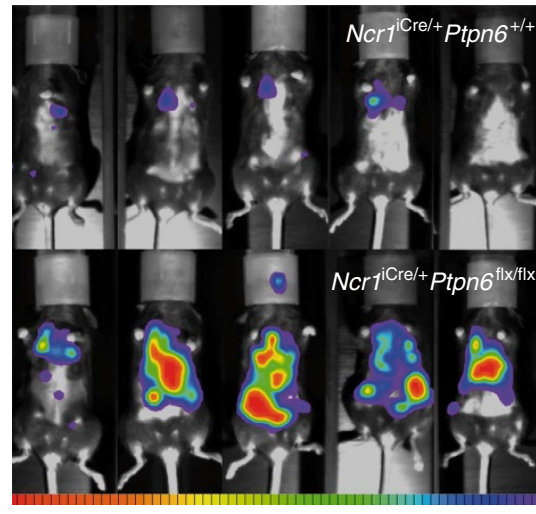

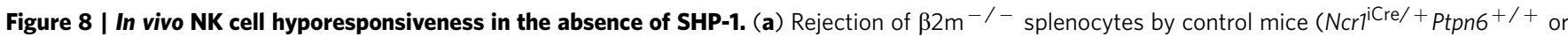

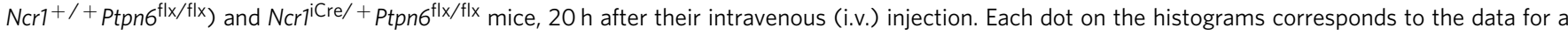
single mouse and the data show the results of four independent experiments. ( $n=12, P<0.0001$, Mann-Whitney). (b) Bioluminescence imaging of $\mathrm{Ncr}^{\mathrm{iCre} /+}$ Ptpn6 ${ }^{+/+}$(top) and $\mathrm{Ncri}^{\mathrm{iCre} /+} \mathrm{Ptpn}^{\mathrm{fl} \times / \mathrm{flx}}$ (bottom) mice, 16 days after the i.v. injection of luciferase ${ }^{+}$B16-melanoma cells. On the right, quantification in photons per second of the bioluminescence from B16-melanoma cells 16 days after i.v. injection $(n=5, P=0.0079$, Mann-Whitney). Each dot on the histograms corresponds to the data for a single mouse.

several lines of evidence to suggest that an intrinsic lack of SHP-1 in NK cells might lead to the impairment of other protein tyrosine kinase-dependent pathways. Indeed, SHP-1 can control the activation of SFK members ${ }^{44}$. In addition, formation of the Ly49 repertoire is dependent on the activity of the SFK member $\mathrm{Fyn}^{57}$. As we show here that the absence of SHP-1 leads to an impairment of $\mathrm{iCa}^{2+}$ mobilization on Ly49D or NKG2D engagement, the model that best fits our data is the desensitization of NK cells in the absence of SHP-1, in a process involving sustained protein tyrosine kinase-dependent activation. The duration of exposure of NK cells to endogenous signals likely to trigger their desensitization is a key factor. The formal demonstration of the involvement of Fyn, Vav1, SLP-76 or PLC- $\gamma$ in this process will thus require the generation of inducible models of NK cell-specific gene deletions, such as NKp46-iCre/ ER knock-in mice. Regardless of the results obtained in such experiments, the role of SHP-1 in NK cell education described here is consistent with our previous findings that the confinement of activating receptors to the plasma membrane plays a key role in ensuring the self-tolerance of NK cells ${ }^{36}$. Indeed, it is possible that in the absence of inhibition mediated by MHC class I receptors, activating receptors engaged due to frequent encounters with endogenous ligands might migrate to the actin meshwork within the membrane, thereby contributing to the hyporesponsiveness of NK cells.

Thus, our data support a model in which SHP-1 is required for the maintenance of a functional NK cell repertoire. SHP-1expressing NK cells are functionally competent in terms of their activation receptors. By contrast, SHP-1-deficient NK cells have no functional self-MHC class I-specific inhibitory receptors and are hyporeactive. However, in both situations NK cells are selftolerant. SHP-1-expressing NK cells are tolerant because they have functional inhibitory receptors for self-MHC class I, and SHP-1-deficient NK cells are tolerant because of their hyporesponsiveness. To the best of our knowledge, the description of this adaptive response of NK cells involving SHP-1 constitutes the first report of an immune tolerance strategy of this type.

\section{Methods}

Mice. $N c r 1^{\mathrm{iCre} /+}$ mice have been described elsewhere ${ }^{10}$. Ptpn $6^{\mathrm{flx} / \mathrm{flx}}$ mice were obtained from the Jackson Laboratory. Ptpn6 is located on mouse chromosome 6, close to the NK gene $(N k c)$ complex. We therefore backcrossed $N c r 1^{\text {iCre/ }+}$ $P t p n 6^{\mathrm{flx} / \mathrm{flx}}$ mice to obtain recombinant animals with an $N k c$ complex of C57/BL/6 origin, as demonstrated by the cell surface expression of NK1.1 on NK cells from $N c r 1^{\text {iCre } /+}$ Ptpn $6^{\mathrm{flx} / \mathrm{fl} x}$ mice. Mice were bred and maintained under specific pathogen-free conditions at the Centre d'explorations physio-pathologiques avancées in Marseilles. Female and male mice of 6-12 weeks were used for the experiments. Mice were maintained in specific pathogen-free conditions and all experiments were done in accordance with institutional committees and French and European guidelines for animal care.

Cell preparation. Splenocyte suspensions were obtained by the mechanical disruption of mouse spleen, and blood cells were then lysed in RBC lysis solution (eBioscience). Splenocytes were used for NK cell marker analyses, in vitro experiments concerning NK cell activation and enriched NK cell production. Preparations enriched in NK cells with the NK Cell Isolation Kit II (Miltenyi Biotec) were used for $\mathrm{Ca}^{2}+$ flux and PtdIns $(3,4,5) P_{3}$ determinations and for LAK cell production. LAK cells were obtained after 7 days of culture with IL-2 (5,000 $\mathrm{U} \mathrm{ml}^{-1}$, Chiron). LAK cells were used for SHP-1 western blottings and in vitro experiments. Cell purity, assessed by flow cytometry, was $70-80 \%$ for cell preparations enriched in NK cells and 95-99\% for LAK cells. Mice were anaesthetized and immediately perfused with PBS before the collection of the liver and gut. Livers were mechanically disrupted in PBS, in a cell strainer, and the cell suspensions were washed three times with PBS. Samples were then enriched in lymphocytes by centrifugation on a Percoll gradient (GE Healthcare). Cells from the small intestine were prepared as previously described ${ }^{58}$. In brief, $2-$ to $3-\mathrm{cm}$ intestine pieces were washed three times with PBS $1 \times$ and then incubated at $37^{\circ} \mathrm{C}$ during $15 \mathrm{~min}$ in $20 \mathrm{ml}$ of PBS $1 \times$, HEPES $1 \mathrm{M}$, EDTA $0.5 \mathrm{M}$ and FCS $10 \%$ before a final wash in RPMI 10\% FCS. The tissues were then incubated three times at $37^{\circ} \mathrm{C}$ during $15 \mathrm{~min}$ in $20 \mathrm{ml}$ of RPMI, $10 \%$ FCS, HEPES $1 \mathrm{M}$ and collagenase VIII (Sigma) $300 \mathrm{UI} \mathrm{ml}^{-1}$. At each round of digestion, intestinal cells were harvested in the supernatant, washed in RPMI, 10\% FCS and enriched in lymphocytes by centrifugation on Percoll gradient. Blood cell counts were quantified by flow cytometry using Trucount tubes (BD Biosciences).

Flow cytometry. Flow cytometry analysis was performed on a BD LSR II (four laser Blue/Red/Violet/utraviolet flow cytometry analyser, BD Biosciences). Antibodies against ROR $\gamma$ t-PE (AFKJS-9 1/50), NKp46-PreCP (29A1.4 1/100), CD49dPE (DX5 1/400), CD49a-APC (Ha31/8 1/400), CD27-PE (LG.3A10 1/100), CD11bV450 (M1/70 1/600), Ly49G2-PC7 (4D11 1/400), Ly49A-V450 (Ye1/48.10.6 1/ 400), Ly49F-PE (HBF-719 1/200), Ly49C/I-biot (5E6), Ly49H-APC (3D10 1/400), Ly49D-FITC (4E5 1/800), NKG2A-biot (16a11 1/100), NKG2D-PE (Cx5 1/50), KLRG1 (2F1 1/400), CD107a-FITC (1D4B 1/50) and IFN- $\gamma$-A647 (XMG1.2 1/200) NK1.1-PC7 (PK136 1/400) were obtained from eBioscience, Biolegend and BD Biosciences, and stained with LIVE/DEAD Fixable Dead Cell Stain (Molecular Probes).

In vitro cell activation. For the measurement of IFN- $\gamma$ production, splenocytes were activated with cytokines $\left(25 \mathrm{ng} \mathrm{ml}^{-1} \mathrm{IL}-12\right.$ from eBioscience and $20 \mathrm{ng} \mathrm{ml}^{-1}$ 
IL-18 from MBL) or in 96-well plates coated with anti-NK1.1 antibody (30 $\mu \mathrm{g} \mathrm{ml}^{-1}$, eBioscience) or Ly49D $\left(30 \mu \mathrm{g} \mathrm{ml}^{-1}\right.$, BD Biosciences). LAK cells were coincubated with YAC-1 cells in various ratios (effector/target): 4/1, 2/1 and 1/1. Cells were activated by incubation with monensin and brefeldin A (GolgiPlug and GolgiStop BD) in complete medium for $4 \mathrm{~h}$ at $37^{\circ} \mathrm{C}$. The cells were subjected to surface staining, then fixed with $1 \%$ paraformaldehyde and permeabilized with Perm/Wash solution (BD Biosciences) before IFN- $\gamma$ staining. Cytotoxicity assays were performed with LAK cells coincubated for $4 \mathrm{~h}$ at $37^{\circ} \mathrm{C}$ with target cell lines (YAC-1, RMA and RMA-Rae1, at a ratio of 10/1) preloaded with ${ }^{51} \mathrm{Cr}$. The chromium released into culture supernatants was quantified in LumaPlate TopCount NXT microplate scintillation (Perkin Elmer).

$\mathbf{C a}^{\mathbf{2}}+$ mobilization. Preparations enriched in NK cells were loaded by incubation for $1 \mathrm{~h}$ at $37^{\circ} \mathrm{C}$ with Indo-1/AM ( $5 \mu \mathrm{M}$ final concentration, Calbiochem) in Hank's balanced salt solution (with $\mathrm{Ca}^{2}+$ and $\mathrm{Mg}^{2}+$, without phenol red, PAA). Cells were washed and stained with anti-CD3-FITC and anti-NKp46-Alexa660 antibodies. Before acquisition, each tube $\left(10^{6}\right.$ cells per $\left.\mathrm{ml}\right)$ was warmed at $37^{\circ} \mathrm{C}$ for $10 \mathrm{~min}$. NK cells were activated with biotin-conjugated antibodies against NKG2D (eBioscience) or Ly49D (eBioscience). Thirty seconds before Ly49D activation, NK cells are inhibited or not with biotin-conjugated antibodies against NKG2A (eBioscience) or Ly49C/I (BD Biosciences). The antibodies were used at a final concentration of $2.5 \mu \mathrm{g} \mathrm{ml}^{-1}$ and were cross-linked with ImmunoPure streptavi$\operatorname{din}\left(10 \mu \mathrm{g} \mathrm{ml}^{-1}\right.$, Pierce), after $2 \mathrm{~min}$ of acquisition. Changes in intracellular $\mathrm{Ca}^{2+}$ concentration over the time were monitored with the Indo-1 (violet) and Indo-1 (blue) channels on an LSR II UV flow cytometry analyser. Peak $\mathrm{iCa}^{2+}$ mobilization and the area under the curve (AUC) are indicated as a \% inhibition as follows:

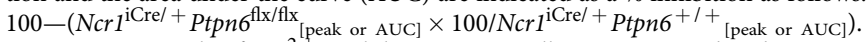
As positive controls of $\mathrm{iCa}^{2}$ mobilization, NK cells were activated with ionomycine $\left(1 \mu \mathrm{g} \mathrm{ml}^{-1}\right.$, Sigma).

Quantification of the phosphoinositides by mass spectrometry. We stimulated one million cells of an NK cell-enriched preparation by incubation with an Ly49D antibody cross-linked to $\mathrm{F}(\mathrm{ab})$ '2 2 for 1 or $5 \mathrm{~min}$, as indicated, in $170 \mu \mathrm{l}$ of PBS containing $2 \mathrm{mM}$ EDTA and $0.05 \%$ FCS. Reactions were stopped by adding $750 \mu \mathrm{l}$ $\mathrm{CHCl}_{3} / \mathrm{MeOH} / 1 \mathrm{M} \mathrm{HCl}(\mathrm{v} / \mathrm{v} / \mathrm{v}: 10 / 20 / 1)$, phosphoinositides were extracted and PtdIns $(3,4,5) P_{3}$ molecular species were quantified by mass spectrometry ${ }^{45}$. Briefly, phosphoinositides were extracted with a two-phase system in which the lower organic phase contained lipids. The internal standard was added and phosphoinositides were derivatized by adding trimethylsilyl-diazomethane. The reaction was quenched by adding glacial acetic acid and phosphoinositides were extracted with the two-phase system. The organic phase was dried under an $\mathrm{N}_{2}$ stream, resuspended in $100 \mu \mathrm{l}$ of $\mathrm{MeOH} / \mathrm{H}_{2} \mathrm{O}(\mathrm{v} / \mathrm{v}:$ 80/20) and subjected to mass spectrometry analysis by the lipidomics core facility of MetaToul and Inserm U1048-I2MC.

Immunoblotting. SHP-1 immunoblotting was performed with LAK cells. LAK cells were lysed with lysis buffer (25 mM HEPES, $150 \mathrm{mM} \mathrm{NaCl}, 1 \%$ NP40, $10 \mathrm{mM}$ $\mathrm{MgCl}_{2}, 1 \mathrm{mM}$ EDTA, $2 \%$ glycerol and protease inhibitor cocktail tablets (Roche)). Protein assays were performed with a BCA kit (Pierce). We then subjected $10 \mu \mathrm{g}$ of protein in LDS sample buffer (Invitrogen) to electrophoresis in a $4-12 \%$ Bis-Tris precast gel in MOPS SDS running buffer (Invitrogen). The bands obtained were transferred onto a nitrocellulose membrane with the iBlot Dry blotting system (Life Technologies). The membrane was saturated by incubation for $1 \mathrm{~h}$ with $0.5 \%$ Tween 20,5\% milk in PBS, stained with antibodies against SHP-1 (C-19, Santa Cruz) and then incubated with an anti-rabbit-horseradish peroxidase secondary antibody (Jackson Immunoresearch). Antibody binding was detected with an ECL kit (Amersham). After stripping, the same experiment is performed for $\beta$-actin revelation.

$\boldsymbol{\beta 2 m}$ Rejection. Splenocytes from $\beta 2 \mathrm{~m}^{-/-}$mice were labelled with Dye eFluor $450(10 \mu \mathrm{M}$, eBioscience) and splenocytes from wild-type mice were labelled with CFSE ( $3 \mu \mathrm{M}$, Life Technologies). In total, we mixed $10 \times 10^{6}$ cells of each population at a ratio of $1: 1$ and injected them intravenously into the mice. We harvested the spleens of the recipient mice $20 \mathrm{~h}$ later, and analysed the presence of labelled donor cells by flow cytometry. Percentage rejection $=100-([(\% \beta 2 \mathrm{~m} / \% \mathrm{wt})$ output $] /[(\% \beta 2 \mathrm{~m} / \% \mathrm{wt})$ input $] \times 100)$.

B16-luciferase injection. B16-luciferase melanoma cells were injected into the tail vein $\left(3 \times 10^{5}\right.$ per mouse). Luciferase expression was then monitored by bioluminescence imaging. We injected luciferin (OZ Biosciences) intraperitoneally into the mice ( $3 \mathrm{mg}$ per mouse). After $15 \mathrm{~min}$, the mice were anaesthetized and placed in a NightOwl LB981 in vivo Imager (Berthold Technologies). We used Berthold Technologies software to determine the number of photons emitted per second.

Statistics. Statistical significance was determined for Mann-Whitney tests and two-way analysis of variance with Bonferroni correction (Prism 5, GraphPad Software). The degree of significance is indicated as follows: ${ }^{\star} P<0.05,{ }^{* *} P<0.01$,
${ }^{* * *} P<0.001$ and ${ }^{* * * *} P<0.0001$. Sample size calculation was based on Student's or analysis of variance statistics $(\alpha=5 \%, 1-\beta$ (power) $=80 \%$, two-sided, to detect differences between groups $\geqq 1.5$ s.d.). According to these criteria, the minimum number of sample per group should be $n=8$.

\section{References}

1. Spits, H. et al. Innate lymphoid cells--a proposal for uniform nomenclature. Nat. Rev. Immunol. 13, 145-149 (2013).

2. Vivier, E. et al. Innate or adaptive immunity? The example of natural killer cells. Science 331, 44-49 (2011).

3. Klose, C. S. et al. Differentiation of type 1 ILCs from a common progenitor to all helper-like innate lymphoid cell lineages. Cell 157, 340-356 (2014).

4. Vidal, S. M., Khakoo, S. I. \& Biron, C. A. Natural killer cell responses during viral infections: flexibility and conditioning of innate immunity by experience. Curr. Opin. Virol. 1, 497-512 (2011).

5. Newman, K. C. \& Riley, E. M. Whatever turns you on: accessory-cell-dependent activation of NK cells by pathogens. Nat. Rev. Immunol. 7, 279-291 (2007).

6. Schmidt, S., Zimmermann, S. Y., Tramsen, L., Koehl, U. \& Lehrnbecher, T. Natural killer cells and antifungal host response. Clin. Vaccine Immunol. 20, 452-458 (2013).

7. Paust, S. \& von Andrian, U. H. Natural killer cell memory. Nat. Immunol. 1, 500-508 (2011).

8. Sun, J. C., Beilke, J. N. \& Lanier, L. L. Adaptive immune features of natural killer cells. Nature 457, 557-561 (2009).

9. Raulet, D. H. Missing self recognition and self tolerance of natural killer (NK) cells. Semin. Immunol. 18, 145-150 (2006).

10. Brodin, P., Karre, K. \& Hoglund, P. NK cell education: not an on-off switch but a tunable rheostat. Trends Immunol. 30, 143-149 (2009).

11. Yokoyama, W. M. \& Kim, S. How do natural killer cells find self to achieve tolerance? Immunity 24, 249-257 (2006).

12. Kärre, K., Ljunggren, H. G., Piontek, G. \& Kiessling, R. Selective rejection of $\mathrm{H}$-2-deficient lymphoma variants suggests alternative immune defense strategy. Nature 319, 675-678 (1986).

13. Bix, M., Liao, N. -S., Zijlstra, M., Loring, J., Jaenisch, R. \& Raulet, D. Rejection of class I MHC-deficient haemopoietic cells by irradiated MHC-matched mice. Nature 349, 329-331 (1991).

14. Raulet, D. H. \& Vance, R. E. Self-tolerance of natural killer cells. Nat. Rev. Immunol. 6, 520-531 (2006).

15. Kim, S. et al. Licensing of natural killer cells by host major histocompatibility complex class I molecules. Nature 436, 709-713 (2005).

16. Fernandez, N. C. et al. A subset of natural killer cells achieves self-tolerance without expressing inhibitory receptors specific for self-MHC molecules. Blood 105, 4416-4423 (2005).

17. Anfossi, N. et al. Human NK cell education by inhibitory receptors for MHC class I. Immunity 25, 331-342 (2006).

18. Belanger, S. et al. Impaired natural killer cell self-education and "missing-self" responses in Ly49-deficient mice. Blood 120, 592-602 (2012).

19. Jonsson, A. H. \& Yokoyama, W. M. Natural killer cell tolerance licensing and other mechanisms. Adv. Immunol. 101, 27-79 (2009).

20. Joncker, N. T., Fernandez, N. C., Treiner, E., Vivier, E. \& Raulet, D. H. NK cell responsiveness is tuned commensurate with the number of inhibitory receptors for self-MHC class I: the rheostat model. J. Immunol. 182, 4572-4580 (2009).

21. Daeron, M., Jaeger, S., Du Pasquier, L. \& Vivier, E. Immunoreceptor tyrosinebased inhibition motifs: a quest in the past and future. Immunol. Rev. 224, 11-43 (2008)

22. Long, E. O., Kim, H. S., Liu, D., Peterson, M. E. \& Rajagopalan, S. Controlling natural killer cell responses: integration of signals for activation and inhibition. Annu. Rev. Immunol. 31, 227-258 (2013).

23. Peterson, M. E. \& Long, E. O. Inhibitory receptor signaling via tyrosine phosphorylation of the adaptor Crk. Immunity 29, 578-588 (2008).

24. Liu, D., Peterson, M. E. \& Long, E. O. The adaptor protein Crk controls activation and inhibition of natural killer cells. Immunity 36, 600-611 (2012).

25. Bessoles, S., Angelov, G. S., Back, J., Leclercq, G., Vivier, E. \& Held, W. Education of murine NK cells requires both cis and trans recognition of MHC class I molecules. J. Immunol. 191, 5044-5051 (2013).

26. Chalifour, A. et al. A Role for cis Interaction between the Inhibitory Ly49A receptor and MHC class I for natural killer cell education. Immunity 30, 337-347 (2009).

27. Lowin-Kropf, B., Kunz, B., Beermann, F. \& Held, W. Impaired natural killing of MHC class i-deficient targets by NK cells expressing a catalytically inactive form of SHP-1. J. Immunol. 165, 1314-1321 (2000).

28. Lorenz, U. SHP-1 and SHP-2 in T cells: two phosphatases functioning at many levels. Immunol. Rev. 228, 342-359 (2009).

29. Narni-Mancinelli, E. et al. Fate mapping analysis of lymphoid cells expressing the NKp46 cell surface receptor. Proc. Natl Acad. Sci. USA 108, 18324-18329 (2011). 
30. Pao, L. I. et al. B cell-specific deletion of protein-tyrosine phosphatase Shp1 promotes B-1a cell development and causes systemic autoimmunity. Immunity 27, 35-48 (2007).

31. Tessmer, M. S. et al. KLRG1 binds cadherins and preferentially associates with SHIP-1. Int. Immunol. 19, 391-400 (2007).

32. Grundemann, C. et al. The NK receptor KLRG1 is dispensable for virusinduced $\mathrm{NK}$ and $\mathrm{CD} 8+\mathrm{T}$-cell differentiation and function in vivo. Eur. J. Immunol. 40, 1303-1314 (2010).

33. Huntington, N. D. et al. NK cell maturation and peripheral homeostasis is associated with KLRG1 up-regulation. J. Immunol. 178, 4764-4770 (2007).

34. Corral, L., Hanke, T., Vance, R. E., Cado, D. \& Raulet, D. H. NK cell expression of the killer cell lectin-like receptor G1 (KLRG1), the mouse homolog of MAFA, is modulated by MHC class I molecules. Eur. J. Immunol. 30, 920-930 (2000).

35. Brodin, P., Lakshmikanth, T., Karre, K. \& Hoglund, P. Skewing of the NK cell repertoire by MHC class I via quantitatively controlled enrichment and contraction of specific Ly49 subsets. J. Immunol. 188, 2218-2226 (2012).

36. Guia, S., Jaeger, B. N., Piatek, S., Mailfert, S., Trombik, T. \& Fenis, A. et al. Confinement of activating receptors at the plasma membrane controls natural killer cell tolerance. Sci. Signal. 4, ra21 (2011).

37. Chicanne, G. et al. A novel mass assay to quantify the bioactive lipid PtdIns3P in various biological samples. Biochem. J. 447, 17-23 (2012).

38. Hoglund, P. et al. Recognition of beta 2-microglobulin-negative (beta $2 \mathrm{~m}$-) $\mathrm{T}$-cell blasts by natural killer cells from normal but not from beta $2 \mathrm{~m}$ - mice: nonresponsiveness controlled by beta $2 \mathrm{~m}$ - bone marrow in chimeric mice. Proc. Natl Acad. Sci. USA 88, 10332-10336 (1991).

39. Oberg, L. et al. Loss or mismatch of MHC class I is sufficient to trigger NK cell-mediated rejection of resting lymphocytes in vivo-role of KARAP/ DAP12-dependent and -independent pathways. Eur. J. Immunol. 34, 1646-1653 (2004).

40. Takeda, K. et al. IFN-\{gamma\} production by lung NK cells is critical for the natural resistance to pulmonary metastasis of B16 melanoma in mice. J. Leukoc. Biol. 90, 777-785 (2011).

41. Johnson, D. J. et al. Shp1 regulates T cell homeostasis by limiting IL-4 signals. J. Exp. Med. 210, 1419-1431 (2013).

42. Iype, T., Sankarshanan, M., Mauldin, I. S., Mullins, D. W. \& Lorenz, U. The protein tyrosine phosphatase SHP-1 modulates the suppressive activity of regulatory T cells. J. Immunol. 185, 6115-6127 (2010).

43. Abram, C. L., Roberge, G. L., Pao, L. I., Neel, B. G. \& Lowell, C. A. Distinct roles for neutrophils and dendritic cells in inflammation and autoimmunity in motheaten mice. Immunity 38, 489-501 (2013).

44. Rhee, I. \& Veillette, A. Protein tyrosine phosphatases in lymphocyte activation and autoimmunity. Nat. Immunol. 13, 439-447 (2012).

45. Mahmood, S., Kanwar, N., Tran, J., Zhang, M. L. \& Kung, S. K. SHP-1 phosphatase is a critical regulator in preventing natural killer cell self-killing. PLoS ONE 7, e44244 (2012).

46. Veillette, A. SLAM-family receptors: immune regulators with or without SAP-family adaptors. Cold Spring Harb. Perspect. Biol. 2, a002469 (2010).

47. Chan, C. J., Andrews, D. M. \& Smyth, M. J. Receptors that interact with nectin and nectin-like proteins in the immunosurveillance and immunotherapy of cancer. Curr. Opin. Immunol. 24, 246-251 (2012).

48. Coudert, J. D., Scarpellino, L., Gros, F., Vivier, E. \& Held, W. Sustained NKG2D engagement induces cross-tolerance of multiple distinct NK cell activation pathways. Blood 111, 3571-3578 (2008).
49. Oppenheim, D. E., Roberts, S. J., Clarke, S. L., Filler, R., Lewis, J. M. \& Tigelaar, R. E. et al. Sustained localized expression of ligand for the activating NKG2D receptor impairs natural cytotoxicity in vivo and reduces tumor immunosurveillance. Nat. Immunol. 6, 928-937 (2005).

50. Tripathy, S. K., Keyel, P. A., Yang, L., Pingel, J. T., Cheng, T. P. \& Schneeberger, A. et al. Continuous engagement of a self-specific activation receptor induces NK cell tolerance. J. Exp. Med. 205, 1829-1841 (2008).

51. Sun, J. C. \& Lanier, L. L. Tolerance of NK cells encountering their viral ligand during development. J. Exp. Med. 205, 1819-1828 (2008).

52. Fauriat, C., Ivarsson, M. A., Ljunggren, H. G., Malmberg, K. J. \& Michaelsson, J. Education of human natural killer cells by activating killer cell immunoglobulin-like receptors. Blood 115, 1166-1174 (2010).

53. Vivier, E., Nunes, J. A. \& Vely, F. Natural killer cell signaling pathways. Science 306, 1517-1519 (2004).

54. Diefenbach, A. et al. Selective associations with signaling proteins determine stimulatory versus costimulatory activity of NKG2D. Nat. Immunol. 3, 1142-1149 (2002).

55. Upshaw, J. L. et al. NKG2D-mediated signaling requires a DAP10-bound Grb2Vav1 intermediate and phosphatidylinositol-3-kinase in human natural killer cells. Nat. Immunol. 7, 524-532 (2006).

56. Lanier, L. L. Up on the tightrope: natural killer cell activation and inhibition. Nat. Immunol. 9, 495-502 (2008).

57. Lowin-Kropf, B., Kunz, B., Schneider, P. \& Held, W. A role for the src family kinase Fyn in NK cell activation and the formation of the repertoire of Ly49 receptors. Eur. J. Immunol. 32, 773-782 (2002).

58. Luci, C. et al. Influence of the transcription factor RORgammat on the development of $\mathrm{NKp} 46(+)$ cell populations in gut and skin. Nat. Immunol. 10, 75-82 (2009).

\section{Acknowledgements}

We thank the animal facility and flow cytometry research facilities at CIML for technica support, and Alain Trautmann, François Romagné, Jacques Nunès, Marc Daëron, Sabrina Carpentier, Michel Buferne, Frédéric Morisson, Maria-Erica Lopes and all the lab members for stimulating discussions and advice. This work was supported by the European Research Council (THINK Advanced Grant) and by institutional grants from INSERM, CNRS and Aix-Marseille University to C.I.M.L. E.V. is a scholar of the Institut Universitaire de France.

\section{Author contributions}

C.V. and A.F. performed the experiments; G.C. and B.P. performed and supervised the analysis of phosphoinositide metabolism. C.V., S.U. and E.V. designed the research, analysed the data and wrote the manuscript.

\section{Additional information}

Supplementary Information accompanies this paper at http://www.nature.com/ naturecommunications

Competing financial interests: E.V. is the cofounder and a shareholder of Innate Pharma. The remaining authors declare no conflicting financial interest.

Reprints and permission information is available online at http://npg.nature.com/ reprintsandpermissions/

How to cite this article: Viant, C. et al. SHP-1-mediated inhibitory signals promote responsiveness and anti-tumour functions of natural killer cells. Nat. Commun. 5:5108 doi: $10.1038 /$ ncomms6108 (2014) 